\title{
ARQUEOLOGIA PÚBLICA E SUA PRÁXIS SOCIAL: UMA CONTRIBUIÇÃO NECESSÁRIA PARA A PRESERVAÇÃO DE RECURSOS ARQUEOLÓGICOS E INTERAÇÃO SOCIAL
}

PUBLIC ARCHAEOLOGY AND ITS SOCIAL PRAXIS: A NECESSARY CONTRIBUITION TO THE PRESERVATION OF ARCHAEOLOGICAL RESOURCES AND SOCIAL INTERACTION

Laize Carvalho de Sousa

Como citar este artigo:

SOUZA, Laize Carvalho de. Arqueologia Pública e sua práxis social: uma contribuição necessária para a preservação de recursos arqueológicos e interação social.In: Cadernos do Lepaarq, v. XV, n.30., p. 80-97, Jul-Dez. 2018. 


\title{
Arqueologia Pública e sua práxis social: uma contribuição necessária para a preservação de recursos arqueológicos e interação social
}

\author{
Laize Carvalho de Sousa*
}

Resumo: O presente artigo discute a Arqueologia Pública, entendida como uma disciplina destinada a interagir e dialogar com a sociedade. Busca destacar conteúdos relacionados a perspectivas de Arqueologia Pública em projetos arqueológicos identificando o panorama das ações desenvolvidas entre 2011 a 2015 nos estados do Piauí e Rio Grande do Norte, refletindo sobre a relação da Arqueologia Pública num contexto capitalista e a preservação de recursos arqueológicos. O estudo é resultado de uma pesquisa documental em relatórios de pesquisas arqueológicas no IPHAN do Piauí e Rio Grande do Norte e contará com a análise e interpretação gráfica. Os resultados obtidos apontam um número pequeno de projetos com perspectivas em Arqueologia Pública em solo piauiense e potiguar, com destaque às ações de Educação Patrimonial. Sendo assim, propõe-se que é necessário refletir sobre a socialização do conhecimento arqueológico através da interação social para a preservação de recursos arqueológicos.

\section{Palavras Chave:}

Arqueologia Pública; Capitalismo; Preservação.

\begin{abstract}
The present article discusses the Public Archeology, understood as a discipline designed to interact and dialogue with society. It seeks to highlight contents related to the perspectives of Public Archeology in archaeological projects, identifying the panorama of the actions developed between 2011 and 2015 in the states of Piauí and Rio Grande do Norte, reflecting on the relationship of Public Archeology in a capitalist context and the preservation of archaeological resources. The study is the result of a documentary research in the IPHAN of Piauí and Rio Grande do Norte and will feature graphic analysis and interpretation. The results obtained indicate a small number of projects with perspectives in Public Archeology in Piauí and Potiguar soil, with focus on Heritage Education actions. Thus, it we propose the necessity of considering the socialization of archaeological knowledge through social interaction for the preservation of archaeological resources.
\end{abstract}

\section{Keywords:}

Public Archeology; Capitalism; Preservation. 


\section{INTRODUÇÃO}

Para iniciar minha contribuição no campo da Arqueologia Pública, partirei do aspecto de que a preservação do patrimônio é sem dúvida algo essencial para as sociedades, como também é necessária a socialização de informações para que os cuidados com esse sejam de fato executados pelas pessoas.

A relação estabelecida entre o patrimônio e as pessoas é sem dúvida essencial, porque no patrimônio está explícita a herança cultural de cada povo e sociedade. A memória está associada a essa dinâmica da relação existente entre patrimônio e identidade cultural da coletividade social. E como o patrimônio é um importante agente educativo, quando o arqueólogo mantém uma interação com a sociedade vislumbrando a socialização do patrimônio arqueológico através de ações educativas, possibilita que o público entenda que o trabalho realizado pelo/a arqueólogo/a pode ir além da "descoberta" de vestígios.

E uma das formas de socializar o patrimônio arqueológico é através da Arqueologia Pública, por meio de diálogos e interação com a comunidade. Parafraseando Aloísio Magalhães (1997), “a comunidade é a melhor guardiã do seu patrimônio [...]" porque, segundo ele, "só se protege o que se ama, só se ama o que se conhece [...]” (MAGALHÃES, 1997, p. 190). A partir desses diálogos são constituídos mecanismos para se chegar às práticas de preservação e conservação do patrimônio local.

Partindo desse pensamento, é de fundamental importância destacar o papel da Arqueologia Pública que, segundo Bezerra (2011, p. 62), visa “compreender as relações entre as distintas comunidades e o patrimônio arqueológico, considerando o impacto do discurso acadêmico e sua visão de mundo, o lugar de suas narrativas na construção e a gestão dos bens arqueológicos". Uma vez que:

[...] a responsabilidade social e profissional da Arqueologia remete à existência de questões dentro da mesma que vão além de problemas teóricos e metodológicos. Esses temas podem ser considerados questões públicas da Arqueologia, pois estariam situados na interface da Arqueologia com a sociedade. Ambas possuem interesses convergentes e divergentes, visto que a sociedade é formada por um conjunto de indivíduos que estão agrupados ou podem ser reunidos em números segmentos específicos (ex. faixa etária, classe social, grupo profissional, local de moradia, etc.) (FERNANDES, 2007, p. 6-7).

Como foi descrito acima, a responsabilidade social e profissional é inerente à interface da Arqueologia com a sociedade e merece uma análise dentro da perspectiva arqueológica, bem como a implicação do esforço de inserir a práxis social do arqueólogo no processo de interação social e democratização da Arqueologia para a preservação do patrimônio arqueológico.

Outro fator que merece atenção dentro da Arqueologia Pública é saber que ela está ligada à dinâmica das relações capitalistas inseridas nas sociedades contemporâneas. E que os trabalhos no campo da Arqueologia Pública estão afeitos às questões políticas e sociais, as quais contribuem para o interesse da sociedade nos aspectos científicos, econômicos e educacionais.

A importância social da Arqueologia não é apenas com o passado, mas também com atuações que envolvem a compreensão do presente. Nesse sentido, o desafio da Arqueologia Pública é não apenas ser mais uma disciplina, mas ser capaz de atuar de modo a promover o pensamento reflexivo sobre a própria práxis arqueológica em todos os níveis.

Considerando a Arqueologia Pública como um campo de pesquisa destinado a dialogar com a sociedade para garantir a proteção e preservação do patrimônio, busquei apresentar um panorama das ações desenvolvidas em projetos arqueológicos (2011-2015) no Piauí e no Rio Grande do Norte com perspectivas de Arqueologia Pública.

Nesse caminho, almejei compreender como a Arqueologia Pública foi introduzida nos anos de 2011-2015 nos estados do Piaú e do Rio Grande do Norte; argumentar sobre a inserção e/ou importância da Arqueologia Pública em projetos arqueológicos para a preservação do patrimônio cultural arqueológico; e discutir sobre a relação da preservação dos bens culturais e arqueológicos num contexto capitalista, uma vez que, ao mesmo tempo em que ele pode desencadear a destruição 
do patrimônio, pode promover o acesso ao conhecimento deste.

No presente artigo apresento os resultados obtidos a partir da pesquisa documental realizada no Instituto do Patrimônio Histórico e Artístico Nacional (IPHAN), instituição federal criada em 1937, que se constitui como um órgão responsável por preservar, divulgar e fiscalizar os bens culturais brasileiros, além de garantir a utilização desses bens pela atual e futura geração. No IPHAN do Piauí foram disponibilizados para pesquisa 53 relatórios e no IPHAN do Rio Grande do Norte foram disponibilizados 247 relatórios.

De posse desse material disponibilizado pelo IPHAN de cada estado da pesquisa, as informações coletadas foram organizadas em uma tabela (Tabela 1), desenvolvida com a finalidade de se construir um banco de dados, organizando de maneira sistemática as informações para ter-se um panorama quantitativo da presença/ausência de ações desenvolvidas com perspectivas de Arqueologia Pública em projetos arqueológicos entre os anos de 2011 a 2015, nos estados do Piauí e Rio Grande do Norte.

Tabela 1 - Critérios para análise dos relatórios

\begin{tabular}{|l|l|l|l|l|}
\hline Ano & Estado & $\begin{array}{l}\text { Natureza da pesquisa: } \\
\text { acadêmica X Contrato }\end{array}$ & $\begin{array}{l}\text { Presença/a usência: } \\
\text { Educação Patrimo- } \\
\text { nial e/ou Arqueologia } \\
\text { Pública }\end{array}$ & \begin{tabular}{l} 
e público-alvo \\
\hline
\end{tabular} \\
\hline & & & \\
\hline
\end{tabular}

Temos consciência de que nossa discussão é produto reflexivo de uma síntese, organização e interpretação da análise de dados gráficos sobre as informações encontradas nos relatórios de projetos arqueológicos dos estados referentes à pesquisa e que não estaremos isentos do nosso lugar social de fala. Então, empenhamo-nos em oferecer um olhar sobre a Arqueologia Pública e sua Práxis Social: uma contribuição necessária para a preservação de recursos arqueológicos e interação social.

Espero, assim, contribuir para a disseminação de dilemas e reproduzir pensamentos críticos acerca da Arqueologia Pública e ao mesmo tempo fica o convite para uma vigília crítica no contexto brasileiro, pois é um desafio a concretude do desenvolvimento de uma Arqueologia Pública para todos os públicos em meio às dualidades que o sistema capitalista produz.

\section{ARQUEOLOGIA PÚBLICA: PRESERVAÇÃO E INTERAÇÃO SOCIAL}

O conceito de Arqueologia Pública surge em meio às transformações e mudanças de pensamento das sociedades e do fazer científico, após as novas maneiras de pensar e olhar o mundo com o fím da Segunda Guerra Mundial e o advento do pós-modernismo. Como resultado desse processo, as ciências passaram a interagir com os grupos sociais, pois "as pessoas não são suportes passivos de estruturas e de sistema, mas são agentes dos processos sociais" (CONSTANTINO, 1996-1997, p. 12). Novas chaves de interpretações foram consideradas como fonte de pesquisa, levando em consideração a participação social na construção das pesquisas.

A definição de Arqueologia Pública entendida como ação com o povo, voltada para o público, que permite que tenhamos uma ciência aplicada em benefícios das comunidades e segmentos sociais (FUNARI; ROBRANH-GONZÀLEZ, 2006, p.3), emerge nesse contexto de ruptura de ideias. 
Por longos anos a Arqueologia foi uma ciência fechada em si mesma, focada "na única fala dos fazeres técnicos e numa epistemologia cartesiana" (MRZOWSKI, 1999 apud REIS, 2007, p.35), que pouco acreditava que existia algo para ser apreendido com a participação da sociedade nas pesquisas. Mas o pensamento pós-processual veio instaurar um debate crítico e necessário no campo teórico arqueológico. O ideal proposto era entender o passado em conexão com o presente, na prática da interpretação (SHANKS; TILLEY, 1987, p. 260).

As preocupações da Arqueologia pós-processual em torno dos aspectos públicos, políticos e práticos, em defesa de uma responsabilidade social entre academia e público nas discussões da disciplina arqueológica, veio revitalizá-la para não se fechar em si mesma, sem olhar para o mundo e sociedade em que se insere. Uma de suas principais contribuições para a Arqueologia Pública está relacionada à maior visibilidade do contexto histórico e social na produção do conhecimento arqueológico e o reconhecimento dos arqueólogos de sua intransferível missão no comprometimento com os grupos sociais.

A atuação social do/a arqueólogo/a passou a ser um tema de particular relevo e importância para preservação dos recursos arqueológicos. Uma vez que:

[...] a Arqueologia deixou por muito tempo para a equipe de não-arqueólogos (incluindo caçadores de tesouros, amadores, saqueadores e romancistas) a missão de propagar suas descobertas e interpretações, não raro de modo distorcido. Nos últimos anos, todavia, os arqueólogos começaram a introduzir em sua rotina de trabalho diferentes ações referentes à agenda em arqueologia pública, como educação, integração com a comunidade e proteção/preservação de sítios arqueológicos (ROBRAHN-GONZÁLEZ, 2006, p. 65).

Segundo a autora, Robrahn-González (2006), foi a partir da introdução da Arqueologia Pública na práxis arqueológica que as ações de socialização do conhecimento arqueológico foram sistematizadas e desenvolvidas de forma mais adequada. A práxis da Arqueologia Pública descortina-se na interação com o público em que está inserido o trabalho realizado pelo arqueólogo. E desenvolve-se como um campo interdisciplinar, tendo como um de seus principais objetivos possibilitar a interação com a sociedade para a preservação dos recursos arqueológicos (FUNARI; ROBRAHN-GONZÁLEZ, 2006, p.3).

A partir desse novo olhar voltado para a socialização do conhecimento, a pesquisa arqueológica passou a ter um compromisso social, uma prática engajada construindo diálogos com as diferentes comunidades, permitindo que elas façam parte da prática arqueológica nas interpretações sobre o passado, deixando de olhar somente para o passado para assumir seu fazer social na compreensão do presente e envolvimento com o passado.

Essa compreensão e colaboração provindas da participação comunitária também proporciona maior entendimento do pesquisador sobre a relação estabelecida (valorização/vínculo) entre a comunidade e os bens patrimoniais, pois nem sempre os sítios arqueológicos estão ativos nas lembranças das comunidades (SANTOS, et. al, 2012, p.10). Então a Arqueologia pode exercer um papel significante no processo de construção de ligações entre o presente e o passado através da preservação da história e das tradições e da valorização do patrimônio cultural (MCMANAMOM 2000; FUNARI; ROBRAHN-GONZÁLEZ, 2008).

Dentre as várias maneiras que se pode trabalhar com as comunidades é comum a presença de projetos de Educação Patrimonial “[...] um processo permanente e sistemático centrado no patrimônio cultural como instrumento de afirmação da cidadania" (FERNANDES, 2007, p. 62), que dialogam com práticas e perspectivas em Arqueologia Pública. Essas ações educativas possibilitam o desenvolvimento de projetos com uma perspectiva de Arqueologia Pública em sentido amplo, pois busca firmar a cidadania diante do próprio contexto cultural em que os indivíduos estão inseridos.

Dessa maneira, 
[...] à medida que o cidadão se percebe como parte integrante do seu entorno, tende a elevar sua autoestima e valorizar a sua identidade cultural. Essa experiência permite que esse cidadão se torne um agente fundamental da preservação do patrimônio em toda a sua dimensão. O conhecimento adquirido e a apropriação dos bens culturais por parte da comunidade constituem fatores indispensáveis no processo de conservação integral ou preservação sustentável do patrimônio, pois fortalece os sentimentos de identidade e pertencimento da população residente, e ainda, estimula a luta pelos seus direitos, bem como o próprio exercício da cidadania. (PELEGRINI, 2006, p. 127).

Como foi citado acima, para que essa identidade seja fortalecida é necessária a aquisição do conhecimento e apropriação dos bens culturais que favorecem a preservação do patrimônio. É a partir de conhecimentos adquiridos que os cidadãos se formam agentes fundamentais de preservação em todas as suas dimensões.

Um relacionamento profícuo dentro da comunidade fornece a Arqueologia Pública à produção de conhecimento, gera cidadania, e, assim, transforma-se em processo dinâmico de transformação social. Pois "a razão última para nossa ação é trabalhar para e com tais públicos" (FUNARI, et al., 2008, p. 131), para fortalecer a concepção de agentes em defesa do patrimônio, conhecendo primeiro a realidade do que eles consideram como patrimônio, assim, a atuação do profissional de arqueologia alcança sua proposta ética.

Nessa aproximação com a comunidade, o arqueólogo deve valorizar e respeitar as diferenças que os grupos sociais atribuem às suas vivências, garantindo a diversidade de conhecimento acerca do passado em que se considere a pluralidade significativa de reapropriações e ressignificações do patrimônio arqueológico pelas pessoas. Envolvendo as pessoas no fazer Arqueologia, desmitificando a ideia de que o arqueólogo veio buscar tesouros escondidos debaixo da terra, ou que veio "levar" informação, veio "levar" patrimônio.

Nesse sentindo, a relação simétrica estabelecida, pensando junto com a população questões relacionadas ao patrimônio, possibilitará a atuação da Arqueologia Pública a partir das demandas das pessoas, reafirmando a relação que elas querem estabelecer com o patrimônio, reconhecendo os saberes, os fazeres, os valores determinados pela comunidade. Para se saber quais políticas públicas podem ser adotadas, dentro do universo das representações sociais, que promovam a valorização e identidade local.

É necessário, então, discutir junto à comunidade: qual é o papel do arqueólogo? Em que aspectos poderá se contribuir em meio às relações sociais, econômicas e patrimoniais atuantes no interior de empreendimentos econômicos?

O contato e a parceria da comunidade em pesquisas arqueológicas ligadas a empreendimentos econômicos pode trazer uma rica contribuição para a interação com o repertório sociocultural, permitindo o resgate no interior da pesquisa, da dimensão de produção coletiva do conhecimento e da realidade. Isso porque o relacionamento constante e flexível com a comunidade favorece a compreensão dos fatores políticos, sociais, culturais e arqueológicos que se expressam no ambiente da pesquisa arqueológica. Do contrário, a distância entre arqueólogo/a e comunidade compromete a eficácia das ações de Educação Patrimonial e Arqueologia Pública nos projetos de maior envergadura.

Por isso, o papel social do arqueólogo/a dentro da sociedade é tão importante, pois ele aprende com a própria comunidade sobre o olhar que a mesma tem em relação ao patrimônio e através de ferramentas da Arqueologia Pública (diálogos e mediação) se abre um caminho para construir, juntos, sentidos e significados ao patrimônio.

A aproximação do/a arqueólogo/a junto à comunidade estimula o surgimento de um ambiente mais aberto ao compartilhamento de saberes e informações dos fatores que envolvem o aspecto arqueológico dentro da comunidade com as contribuições que ela pode levar para o arqueólogo abranger o universo de trabalho, onde podem surgir novas demandas, isto é, novas pesquisas que podem alargar o patrimônio e até a produção de novas pesquisas que promovam novos conhecimentos. 
Isto porque o patrimônio arqueológico está ligado a laços de "referência à identidade, à ação, e à memória dos diferentes grupos da sociedade", como destaca o artigo 216 da Constituição de 1988. Sendo assim, o/a arqueólogo/a passa a ser um articulador entre patrimônio arqueológico e sociedade, incentivando a comunidade a conhecer a Arqueologia e participar da construção do conhecimento do patrimônio arqueológico.

Na verdade, como dito outrora, o/a arqueólogo/a promove junto à comunidade, através da interação social, possibilidades de definições daquilo que a comunidade considera como patrimônio visando a valorização dos bens arqueológicos e culturais. Ou seja, temos que começar a ouvir mais as pessoas, para que o patrimônio não seja algo simplesmente definido por nós, arqueólogos. Porque, na realidade, definir patrimônio é definir o que queremos que seja preservado. Em outras palavras, é essencial que a interpretação do patrimônio seja elaborada de maneira construtiva.

Dessa forma, realizar diálogos horizontais tem reverberações mais profundas, pois aproxima a comunidade e abre as portas para a participação nas escolhas do que se deseja manter e preservar. Essa troca de diálogos e saberes promove o conhecimento e a interação entre pesquisador e população. Com isso, vem-se derrubando muitas barreiras, sobretudo no que diz respeito à relação entre arqueólogo e sociedade. A sociedade hoje colabora e participa das pesquisas arqueológicas, trazendo um novo olhar para as investigações e descobertas arqueológicas.

\section{OS DESAFIOS DA ARQUEOLOGIA PÚBLICA INSERIDA NUM CONTEXTO CAPITALISTA}

A Arqueologia tem expandido sua atuação no Brasil acompanhando os projetos de desenvolvimento econômico, produzindo, consequentemente, profundas implicações para a atuação do/a arqueólogo/a dentro desse cenário transformador. Emerge nesse contexto o desenvolvimento da Arqueologia de Contrato ${ }^{1}$, uma nova modalidade de pesquisa arqueológica atrelada ao licenciamento ambiental, "sendo uma das missões do arqueólogo envolvido nesses estudos contribuir, no presente, para que a construção do futuro não se faça à custa do passado" (CALDARELLI; SANTOS, 1999-2000, p. 54).

Os instrumentos para a obtenção do licenciamento ambiental são o Estudo de Impacto Ambiental (EIA) e o Relatório de Impacto Ambiental (RIMA). Esses documentos devem conter obrigatoriamente os estudos arqueológicos da área onde será implantado o empreendimento quando os projetos de desenvolvimento econômico forem potencialmente impactantes.

De acordo, com a Resolução CONAMA no 001/86 é preciso avaliar os impactos sobre os bens culturais da comunidade, entender as relações dinâmicas do meio ambiente cultural no sistema sociocultural de uma determinada comunidade e a agência dos bens culturais tão latentes nas populações afetadas pelos empreendimentos no âmbito do licenciamento.

Quando tais aspectos são desconsiderados no licenciamento ambiental há perdas irreparáveis dos bens culturais interferindo diretamente nos chamados "portadores de referência à identidade, à ação e à memória dos diversos grupos formadores da sociedade brasileira".

Com o intuito de mitigar os impactos causados por empreendimentos econômicos atrelados ao capitalismo, a execução destes em território brasileiro se encontra vinculada a licenças ambientais previstas em determinações legais, salvaguardando a possibilidade de preservação do patrimônio arqueológico pré-histórico e histórico (SANTOS, 2011, p. 61), de maneira a conciliar as licenças ambientais com a necessidade de estudos preventivos de Arqueologia.

\footnotetext{
1 "Do ponto de vista do rigor das exigências científicas e da qualidade do conhecimento que deverão produzir, não deve haver diferença substancial entre 'arqueologia acadêmica' e arqueologia contratual, de salvamento, empresarial. A pesquisa arqueológica deve orientar-se, sempre, para a identificação dos sistemas de ocupação territorial, na estrutura, funcionamento e transformações” (MENESES, 2007, p. 45).
}

SOUZA, Laize Carvalho de. Arqueologia Pública e sua práxis social...In: Cadernos do Lepaarq, v. XV, n.30., p. 80-97, 
A aprovação de aportes legais para preservação e proteção do patrimônio arqueológico é um aspecto que contribui de maneira significativa para que na realização de trabalhos arqueológicos ligados à Arqueologia de Contrato ocorra o desenvolvimento de atividades visando a socialização patrimonial por ações junto à comunidade sobre Educação Patrimonial em decorrência da implantação de empreendimentos.

A arqueologia no cenário do licenciamento ambiental está ligada diretamente às relações capitalistas, as pesquisas arqueológicas se apresentam como integrantes do processo de crescimento econômico. No entanto, as relações capitalistas constituírem um desafio para a preservação de recursos arqueológicos que é importante para a compreensão do passado, devido ao modo de apropriação do valor simbólico que este representa para tal sociedade.

Se por um lado nunca houve tanto sítio arqueológico "descoberto" contribuindo para o conhecimento histórico e arqueológico, por outro, o impacto e a degradação ao patrimônio arqueológico são um problema que tem aumentado em larga escala pelos empreendimentos econômicos.

No entanto, a questão é muito mais sensível quando implica no deslocamento compulsório de pessoas que moram em áreas diretamente afetadas pela construção de empreendimentos. Sem levar em conta as associações que as pessoas mantêm com seu meio ambiente cultural, "que agrega valores fundamentais da comunidade, retratando a sua memória, a sua identidade e a sua história" (CORREIA, 2004, p.41). Uma vez que a relação decorrente do meio ambiente e patrimônio cultural reverbera na sociedade.

Diante desse contexto, a exigência de atuação profissional com um comprometimento ético voltado à defesa do patrimônio torna-se emergente, uma vez que o/a arqueólogo/a não pode ficar refém do capital. Sem dúvida um desafio para a atuação profissional.

Mediante esses dilemas do crescimento econômico que necessitam de mediação, a Arqueologia Pública exerce um papel importante no que diz respeito ás questões sociais entre empreendedores, arqueólogos e população, visando à abertura de estratégias que favoreçam o gerenciamento do patrimônio cultural e à clarificação do interesse entre ambos através de diálogos.

A Arqueologia Pública pode contribuir para a identificação e registro dos bens culturais de uma determinada comunidade que não tenha a proteção instituída como elementos importantes do patrimônio cultural brasileiro, no sentido de garantir o conhecimento e a valorização da identidade local dessa população, para que tais bens não venham a ser sumariamente desvalorizados na hora da implantação de projetos de desenvolvimento econômico, por exemplo.

Sendo assim, a Arqueologia Pública é:

[...] um campo de pesquisa debate e aplicação debate e aplicação da Arqueologia, destinado a dialogar com a sociedade sobre as questões públicas da disciplina (legislação, gestão, ética e educação), almejando garantir a proteção e preservação do patrimônio arqueológico, bem como, defender os interesses profissionais, científicos e públicos da Arqueologia. (FERNANDES, 2007, p. 47).

A Arqueologia Pública brasileira se encontra profundamente ligada à Arqueologia de Contrato, atrelada principalmente à prática da Educação Patrimonial (obrigatoriedade da inclusão de Educação Patrimonial em projetos de Arqueologia de Contrato, IN n 001/2015). A Educação Patrimonial desencadeada a partir de projetos de Arqueologia de Contrato relacionada à legislação de proteção ao patrimônio arqueológico envolve em seu processo a construção de um caminho para valorização das identidades culturais, conhecimento e preservação do patrimônio cultural de nossa sociedade. 
Segundo Lima (2014), as ações educativas pertencem ao universo amplo da Arqueologia Pública e são bases importantes para a atuação junto aos diversos sujeitos com os quais a Arqueologia se relaciona. A Educação Patrimonial é uma ferramenta de trabalho da Arqueologia Pública e nas ações educativas seus caminhos se entrecruzam (LIMA, 2014, p. 63).

Por isso é indispensável a atuação não só de Educação Patrimonial, mas também de atividades diretamente relacionadas à Arqueologia Pública que são ferramentas relacionadas às questões sociais em Arqueologia. Partindo desse entendimento de que a preservação de recursos arqueológicos é um dos principais instrumentos para o desenvolvimento da racionalidade patrimonial, a Arqueologia Pública incentiva a reflexão sobre a identificação dos problemas advindos com os empreendimentos para com o patrimônio arqueológico e a busca de índices satisfatórios de desenvolvimento econômico e de preservação do patrimônio cultural e arqueológico.

É interessante ressaltar que a Arqueologia Pública:

[...] surgiu no contexto de globalização, portanto num quadro de franca expansão capitalista, que teve como impulso fundamental a revolução tecnológica. Graças à poderosa expansão tecnológica e de comunicação, a globalização, desde o início, vem se mostrando com uma dupla face: tanto favorece novas oportunidades quanto traz ameaça ao meio ambiente e à sociedade, sobretudo às comunidades tradicionais. (FUNARI; ROBRAHN-GOZÁLEZ, 2008; SANTOS, 2011, p. 66).

Como vimos acima, o contexto de surgimento da Arqueologia Pública tem uma relação direta com o capitalismo, tal relação é bastante divergente sobre a função que o desenvolvimento capitalista pode trazer, pois há uma dualidade: ora o capitalismo vai favorecer o patrimônio ora ameaçá-lo. Sendo assim, as relações capitalistas possuem duas vertentes e é o modo como é trabalhado que define os aspectos positivos e negativos, garantindo ou não a preservação de um determinado patrimônio.

Por isso, como apresenta Silva (2011, p.156), a Arqueologia de Contrato foi duramente criticada por muitos profissionais, devido aos efeitos que o "capitalismo selvagem" pode ter sobre um trabalho essencialmente de pesquisa científica, por outro lado, cumpre lembrar que os trabalhos de Arqueologia de Contrato possibilitaram a socialização da Arqueologia com a realização de ações de cunho educativo patrimonial, como também trouxe consigo a importância das discussões no contexto da Arqueologia Pública no Brasil, por sua relevância política e econômica, além de fomentar as discussões e produções de trabalhos científicos.

Logo, a Arqueologia de Contrato não deve ser vista apenas como uma atividade econômica, mas algo que pode ser agente de transformações sociais e culturais geradas como resultado direto do desenvolvimento econômico sustentável, quando ligada a ações de Arqueologia Pública buscando índices satisfatórios de desenvolvimento econômico e preservação do patrimônio cultural. A Arqueologia Pública exerce um papel de mediadora no processo de articulação de definição de estratégias voltadas à reflexão sobre o desenvolvimento sustentável, discutindo a importância de definir estratégias concretas para dialogar com o empreendedor, com o governo, para fazer propostas de gestão, de público, de mitigação.

\section{DADOS SOBRE ARQUEOLOGIA PÚBLICA EM PROJETOS ARQUEOLÓGICOS (2011-2015)}

A pesquisa permitiu uma análise geral de 300 relatórios de projetos de pesquisas de Arqueologia abrangendo a área acadêmica e projetos por contrato em solo piauiense e potiguar, sendo que, dos 300, apenas 53 correspondem ao universo dos projetos disponibilizados pelo IPHAN-Piauí e 247 foram disponibilizados pelo IPHAN-Rio Grande do Norte. 


\title{
Projetos analisados no Piauí e Rio Grande do Norte
}

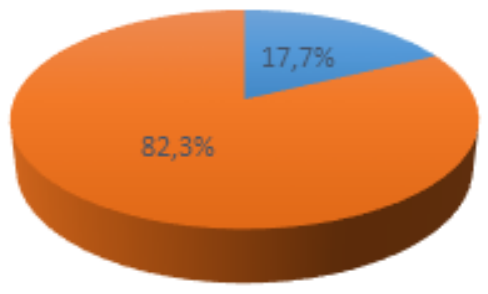

\author{
- Piauí \\ - Rio Grande do Norte
}

Gráfico 1 - Percentual dos projetos analisados no Piauí e Rio Grande do Norte (2011-2015)

Como apresentamos no gráfico acima, o valor percentual dos projetos analisados no estado do Piauí corresponde a $17,7 \%$ do total geral de projetos consultados e $82,3 \%$ do total geral de projetos disponibilizados para a consulta da pesquisa são do Rio Grande do Norte.

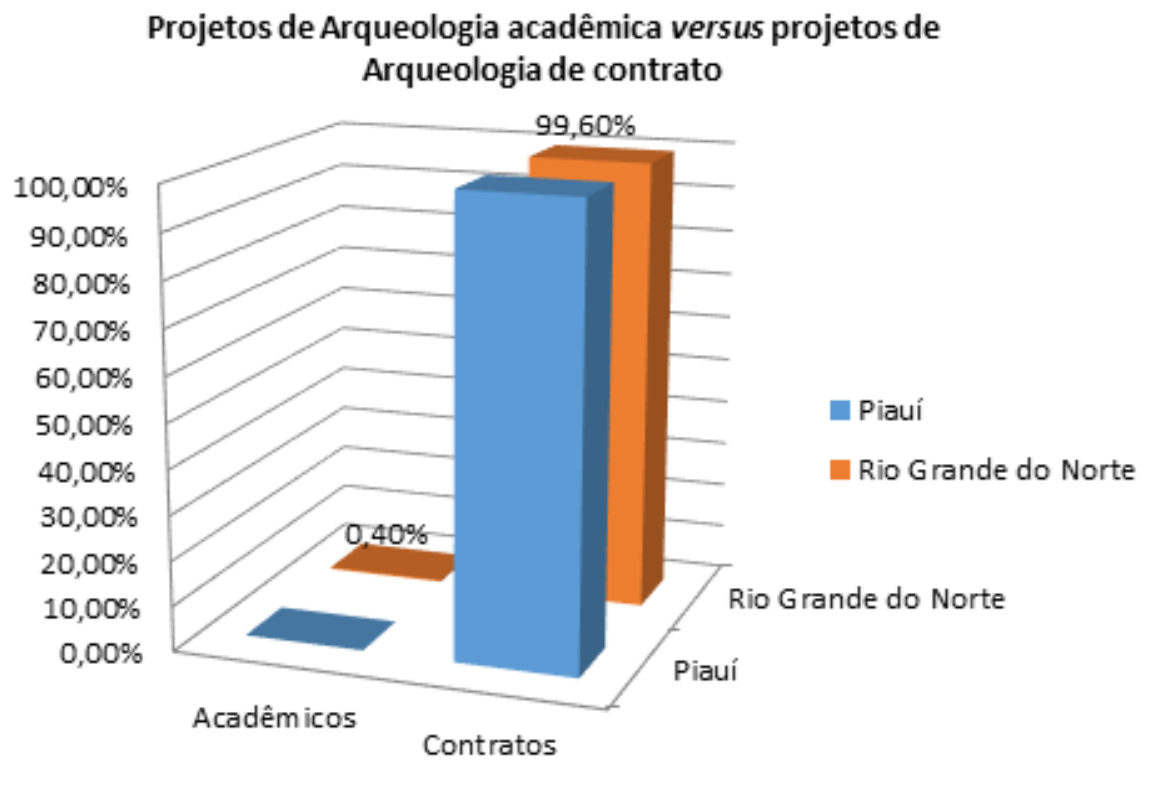

Gráfico 2 - Percentuais dos projetos analisados conforme a área de origem

Diante dos dados referendados pelo gráfico 2, podemos saber que o maior percentual dos projetos analisados corresponde aos projetos de Contrato nos dois estados pesquisados, ou seja, 100\% dos projetos disponibilizados para consulta no IPHAN-Piauí pertencem à área da Arqueologia de Contrato e 99,60\% dos projetos consultados no Rio Grande do Norte também são advindos da Arqueologia de Contrato. Outro aspecto importante a se considerar é que apenas 0,40\% dos projetos disponibilizados pelo IPHAN-RN correspondem à área acadêmica.

Esse gráfico também nos permite compreender que o percentual de projetos por Contrato é maior, se comparado à área Acadêmica devido à abrangência de empreendimentos em solo piauiense e potiguar, favorecendo, assim, projetos na área de Contrato e sua relação com o capital.

O gráfico seguinte tem como objetivo apresentar a proporção da presença/ausência de ações de socialização do patrimônio arqueológico de acordo com o total de projetos analisados para a pesquisa. Ou seja, as ações de Educação Patrimonial e de Arqueologia Pública. 


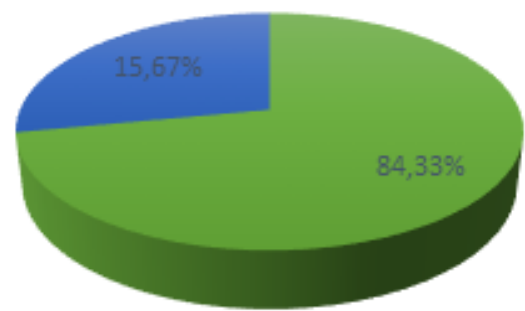

• Presença de ações de socialização do patrimônio

- Ausência de ações de socialização do patrimônio

Gráfico 3 - Proporção da presença/ausência de socialização do patrimônio

Como apresentado no gráfico acima, em números foram $84,33 \%$ de projetos que apresentaram presença de ações voltadas à socialização do patrimônio, sendo verificada a ausência de ações em 15,67\% dos projetos. Dando sequência à análise do gráfico 3, percebe-se que existe uma predominância de pesquisas desenvolvendo ações de Educação Patrimonial e/ou de Arqueologia Pública, e os motivos que nortearam essa configuração se devem ao cumprimento da legislação.

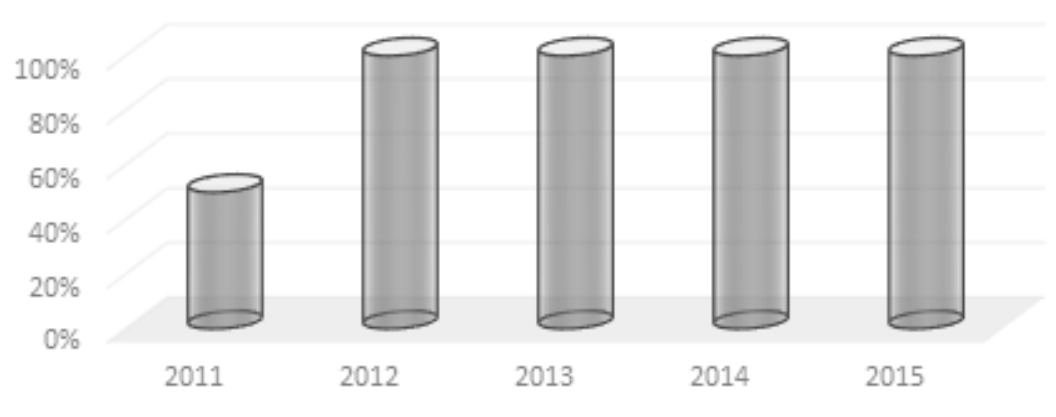

ações de socialização patrimonial no Paiuí (2011-2015)

Gráfico 4 - Ações patrimoniais referentes às pesquisas arqueológicas realizadas no Piauí de 2011 a 2015

Como visualizado no gráfico acima, a grande maioria dos projetos analisados no estado do Piauí apresenta em seus relatórios ações de socialização do patrimônio, isto é, Educação Patrimonial e/ou Arqueologia Pública.

Vale pontuar, ainda, que no período analisado (2011 a 2015) apenas o ano de 2011, considerando os projetos referentes ao estado do Piauí, apresenta 50\% de presença de ações de atividades patrimoniais. Ou seja, os anos seguintes, 2012, 2013, 2014 e 2015, se destacam com 100\% de presença de ações voltadas à socialização do patrimônio cultural e arqueológico.

Pelo gráfico abaixo em exibição é possível observar que há uma tendência de crescimento relativamente constante no número de projetos com ações de socialização do patrimônio no período examinado, no estado do Rio Grande do Norte. Mesmo que, em 2013, esse número tenha um pequeno declínio em relação a 2012, o gráfico passa a ser ascendente a partir de 2013. 


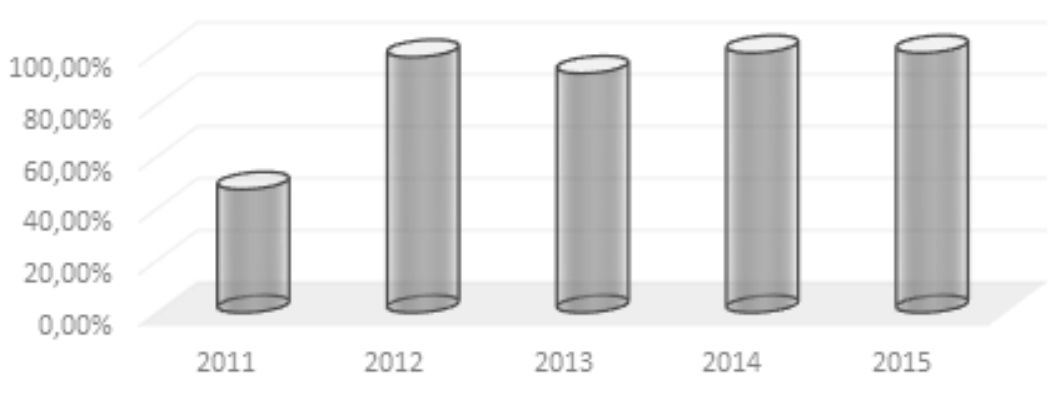

Ações de socializaçãodo patrimonial no Rio Grande do Norte (2011 -2015)

Gráfico 5 - Ações patrimoniais referentes às pesquisas arqueológicas realizadas no Rio Grande do Norte de 2011 a 2015

Diante dos dados apresentados no gráfico 5, podemos saber que o ano de 2011 apresentou 47,50\% de ações educativas, o ano de 2012 apresentou 98,36\%, o ano de 2013 92,10\%, enquanto os anos seguintes, 2014 e 2015, alcançaram 100\% de ações realizadas para a socialização do patrimônio a partir de ações educativas.

Os gráficos (6 e 7) a seguir têm por objetivo apresentar os projetos quanto à presença e/ou ausência de ações que contemplem a socialização do patrimônio arqueológico, de modo a permitir se traçar um cenário em perspectiva do desenvolvimento da Arqueologia Pública nos estados através dos projetos analisados.

O gráfico 6 indica que 92,22\% dos projetos analisados referentes ao estado do Piauí contaram com a realização de ações de Educação Patrimonial, enquanto que apenas 1,89\% dos projetos apresentaram uma perspectiva de Arqueologia Pública para realizar as atividades de socialização do patrimônio arqueológico.

Com relação à ausência de Educação Patrimonial e Arqueologia Pública, o número é relativamente pequeno quando observamos o total de projetos analisados, ou seja, apenas 1,89\% não contaram com ações de cunho patrimonial.

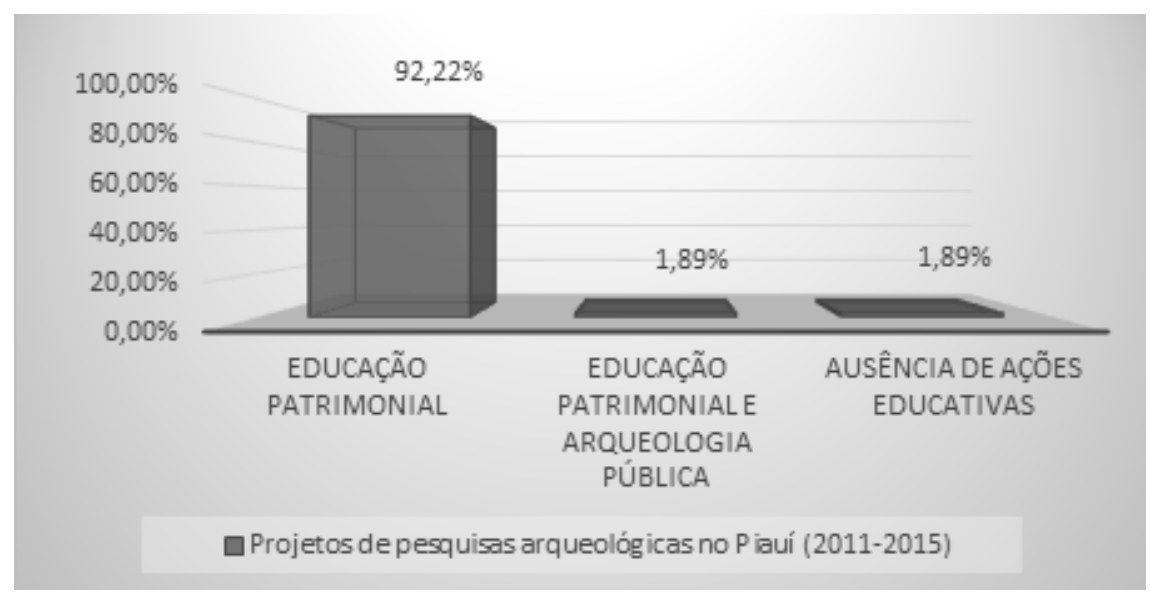

Gráfico 6 - Presença/ausência de ações com perspectivas de Arqueologia Pública em projetos do Piauí

O gráfico 7 informa que o percentual dos projetos analisados no Rio Grande do Norte que desenvolveram atividades de Educação Patrimonial corresponde a mais da metade dos projetos consultados, isto é, 65,18\%. Em outras palavras, apenas $18,62 \%$ dos projetos se caracterizam pela ausência de ações patrimoniais.

Gráfico 7- Presença/ausência de ações com perspectivas de Arqueologia Pública em projetos do Rio Grande do Norte 


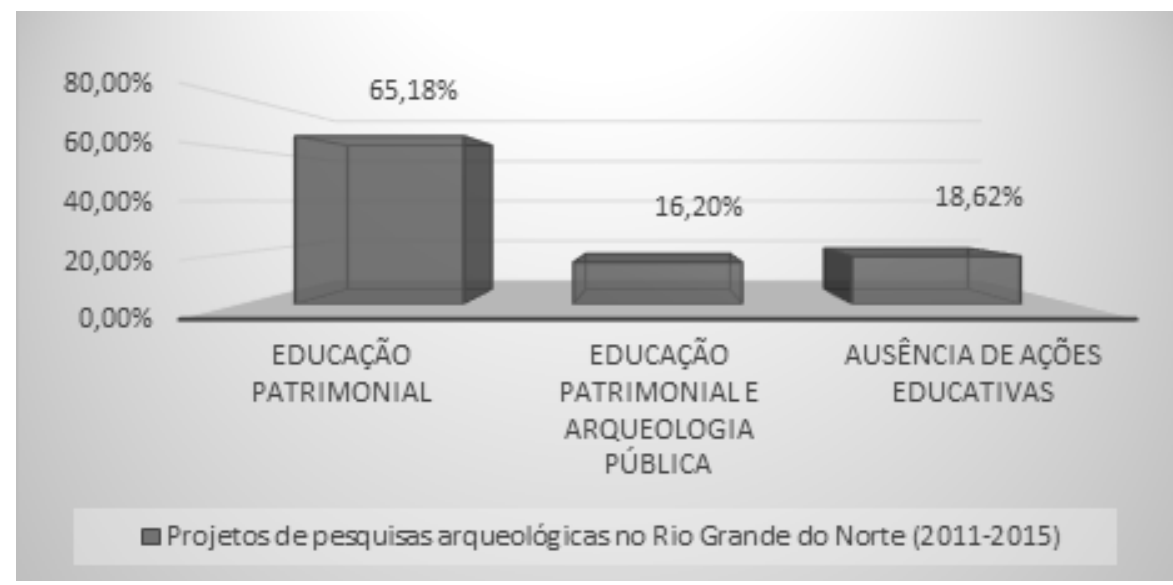

Gráfico 7- Presença/ausência de ações com perspectivas de Arqueologia Pública em projetos do Rio Grande do Norte

Ainda analisando o referido gráfico, nota-se que 16,20\% dos projetos analisados no Rio Grande do Norte apresentaram ações de socialização patrimonial que, segundo os pesquisadores dos projetos, foram norteadas por perspectivas de Arqueologia Pública.

Ainda sobre os relatórios analisados, podemos dizer que houve uma grande semelhança nas ações patrimoniais realizadas nos dois estados pesquisados, como será apresentado, a seguir, nos gráficos 8 e 9.

O gráfico 8 pontua as ações educativas realizadas pelos projetos de pesquisas arqueológicas no estado do Piauí. O que se percebeu é que essas ações foram desenvolvidas como consequência ao cumprimento da legislação referente ao patrimônio, ou seja, todas as ações foram desenvolvidas no âmbito de projetos pertencentes à área da Arqueologia de Contrato. Como foi apresentado no gráfico 2, todos os projetos consultados no IPHAN-PI são advindos da Arqueologia de Contrato.

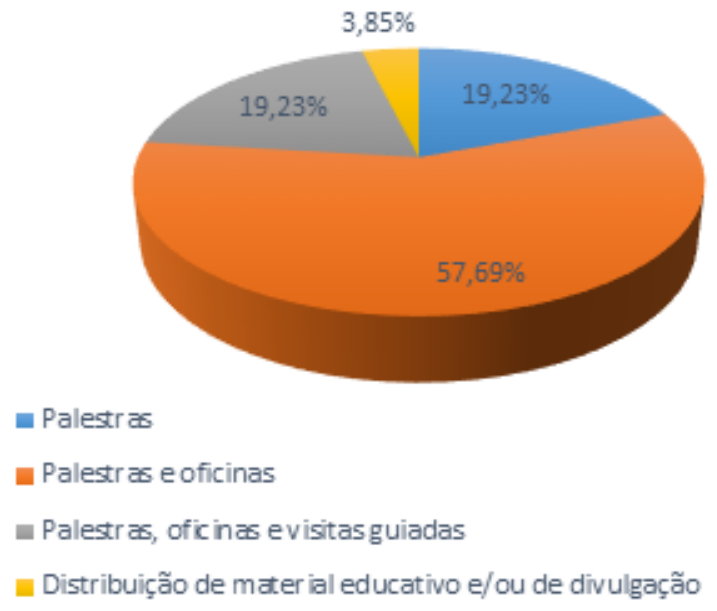

Gráfico 8 - Ações de socialização do patrimônio realizadas no Piauí (2011-2015)

Um ponto importante que não posso deixar de destacar é que 3,85\% das ações correspondem apenas à distribuição de material educativo e/ou distribuição de material de divulgação como ação de socialização. 


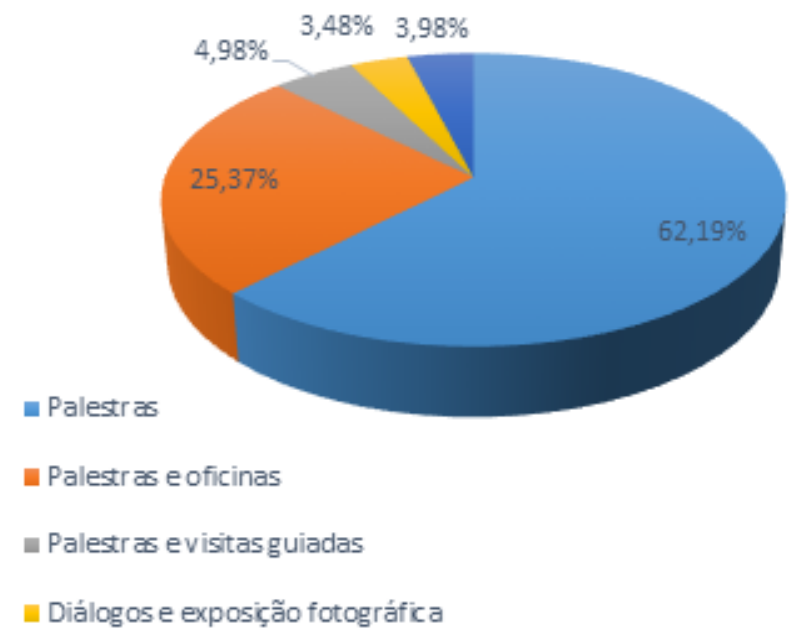

Gráfico 9 - Ações de socialização do patrimônio no Rio Grande do Norte (2011-2015)

No gráfico em exposição acima, é apresentado as ações que se destacaram para a socialização da Arqueologia e do patrimônio no estado do Rio Grande do Norte. Cabe dizer que as ações em forma de palestras correspondem à grande maioria de $62,19 \%$. Em seguida se destacam as ações de palestras e oficinas com $25,37 \%$, ao passo que as ações em forma de palestras e visitas guiadas alcançam 4,98\% e as ações de diálogos e distribuição de material educativo correspondem a 3,98\%.

Ainda em relação ao gráfico 9 acima apresentado, percebe-se que 3,48\% das ações correspondem a diálogos e exposição fotográfica referentes à cultura material encontrada nos sítios arqueológicos. Essas ações desempenharam uma tentativa de interação social entre pesquisador e comunidade, patrimônio e comunidade.

Pelos dados apresentados, gráficos 8 e 9, é possível analisar que uma grande parcela das ações educativas voltadas à socialização do patrimônio cultural se deu através de apresentações de informações e/ou instruções quanto ao patrimônio cultural, tendo como principais recursos na elaboração dos projetos palestras e oficinas. Porém, o objetivo da Educação Patrimonial vai além de uma simples distribuição de materiais educativos e/ou de divulgação, ou de palestras, embora a divulgação seja o início para a preservação das referências culturais que compõem o patrimônio cultural.

Oliveira (2011) aponta que uma ação educativa pode ter uma componente de divulgação, mas não deve ser confundida com esta. Portanto, "a Educação Patrimonial deve se constituir em ações que pressuponham uma intervenção específica com o objetivo de que o indivíduo se aproprie dos bens culturais e os preserve" (DEMARCHI, 2015, p. 209).

A IN no 001/2015 não traz um detalhamento de como deve ser realizada as atividades referentes à Educação Patrimonial. Por outro lado, a instrução normativa trouxe avanços significativos com relação à portaria 230/2002, ao esclarecer pelo artigo $45, \S 4^{\circ}$, que: "As atividades, pontuais, tais como: palestras e ações de caráter exclusivamente promocional, assim como atividade de esclarecimento e divulgação, não são suficientes para caracterizar Projeto Integrado de Educação Patrimonial”.

O que se percebeu sobre as ações de Educação Patrimonial é que há uma necessidade de explanação ou definição acerca dos critérios dos programas ou projetos que incluem a mesma. Assim, essa realidade mostra a fragilidade com que as ações podem ser desenvolvidas, que podem ter implicações, por exemplo, pela ausência de um planejamento adequado com a realidade local. É um risco quando o/a arqueólogo/a segue apenas uma obrigatoriedade legal, precisa-se do comprometimento de todos os envolvidos para que as ações não sejam apenas pontuais. De maneira geral, essas ações de Educação Patrimonial e/ou Arqueologia Pública foram desenvolvidas para a socialização, valorização e preservação do patrimonial cultural e arqueológico junto ao elenco de sujeitos sociais, como apresentado na figura 1, a seguir: 


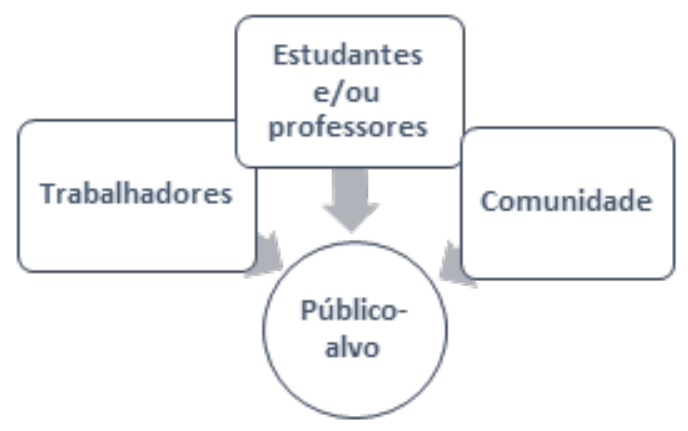

Figura 1- Público-alvo das ações de socialização

É interessante destacar que os atores sociais mais contemplados com as ações de socialização da Arqueologia e do patrimônio cultural são os estudantes, principalmente, crianças e jovens, pois os processos de socialização das atividades relacionadas às ações de Arqueologia Pública, no contexto analisado, se encontram enraizadas às pesquisas arqueológicas por Contratos e, principalmente, às ações de Educação Patrimonial desenvolvidas no ambiente escolar.

A participação social da comunidade em projetos de Arqueologia é indispensável, principalmente para crianças e jovens no desenvolvimento de capacidades de criticidade e de apropriação dos conhecimentos dos bens patrimoniais para construção da cidadania e de sua identidade.

A exigência da Educação Patrimonial representou avanço significativo no contexto da gestão e preservação do patrimônio cultural, ao passo que busca contribuir como um mecanismo para inclusão da sociedade num processo de gestão compartilhada do patrimônio que é, ou deveria ser, coletivo (Fernandes, 2007). Mas, para alcançar uma melhor articulação com a comunidade, as ações devem abandonar ideias feitas e acabadas sobre o discurso e conhecimento arqueológico para o público, e abraçar-se plenamente à reflexibilidade na mediação das relações sociais, a partir de ações educativas, estabelecendo interação entre sociedade e patrimônios.

\section{CONSIDERAÇÕES FINAIS}

O que pretendi aqui foi ressaltar a importância da Arqueologia Pública e sua práxis social como uma contribuição necessária para a socialização da Arqueologia através da interação e diálogos com os diversos públicos na busca da preservação dos recursos arqueológicos, tendo como principal elo a ampliação da participação social na construção do conhecimento arqueológico.

Ficou evidente pelos dados apresentados, tanto do estado do Piaú como do estado do Rio Grande do Norte, que o desenvolvimento das atividades voltadas à socialização do patrimônio necessita de uma elaboração com mais eficácia. Por isso, por mais que os pesquisadores coloquem que os projetos de Educação Patrimonial (gráficos 6 e 7) são norteados por uma perspectiva de Arqueologia Pública, ainda se configura como emergencial a utilização de meios difusos mais eficazes. Pois não basta informar a comunidade sobre a importância de se preservar o patrimônio arqueológico, mas refletir e discutir sobre as relações entre os vestígios e sua relação com as pessoas. Sendo papel da Arqueologia Pública contribuir para a inclusão social a partir do patrimônio e não impor uma leitura acadêmica e vertical da história do patrimônio de uma comunidade.

Embora seja pouco o número de projetos com perspectivas relacionadas à Arqueologia Pública, abre-se um importante espaço para tal importante discussão para que possamos dar novos passos para a inclusão da comunidade nas pesquisas arqueológicas, visto que a inclusão da comunidade em programas educativos torna-se o primeiro passo, em um longo caminho 
para uma Arqueologia Pública que considere os diferentes tipos de saber: tanto científico como da comunidade, de modo que ambos os conhecimentos sejam utilizados para a preservação e gestão dos recursos arqueológicos.

Logo, a Arqueologia através do seu papel social contribui para a promoção, valorização da diversidade cultural e preservação do patrimônio. Como a história sobre a Arqueologia Pública não acabou, é importante enfatizar que é necessário ampliarmos nossos horizontes, e a cada leitura acurada de novas discussões que são realizadas é possível estimular novas reflexões por ser um tema tão vasto e infindo e ao mesmo tempo atingir o seu objetivo central que é a constante interação com a sociedade. 


\section{REFERÊNCIAS}

BEZERRA, Márcia. “As moedas dos índios”: um estudo de caso sobre os significados do patrimônio arqueológico para os moradores da Vila de Joanes, ilha de Marajó, Brasil. Boletim do Museu Paraense Emílio Goeldi Ciências Humanas, Belém, v. 6, n. 1, p. 57-70, jan.- abr., 2011.

CALDARELli, Solange B.; SANTOS, Maria do Carmo M. M. Arqueologia de Contrato no Brasil. Revista USP, São Paulo, n. 44, p. 52-73, dez./fev. 1999/2000.

CONSTANTINO, Núncia Santoro de. Narrativa e história oral. In: Humanas, Porto Alegre, v.19/20, n.1/2, p.115-126, 19961997.

CORREIA, Belize Câmara. A tutela judicial do meio ambiente cultural. Revista de Direito Ambiental. São Paulo: Revista dos Tribunais, v.34, abr.-jun. 2004 p.50.

DEMARCHI, João Lorandi. Patrimônio e Educação: contribuições da rede paulista de educação patrimonial para o tema. Revista CPC, São Paulo, n.20, p.207-215, dez. 2015.

FERNANDES, Tatiana. Vamos criar um sentimento?!Um olhar sobre a Arqueologia pública no Brasil. São Paulo: USP. 2007. 211 f. Dissertação (Mestrado em Arqueologia). Museu de Arqueologia e Etnologia, Universidade de São Paulo, 2007.

FUNARI, Pedro Paulo A; ROBRAHN-GONZÁLEZ, Erika Marion. Editorial. Revista Arqueologia Pública, São Paulo, n.1, p.3, 2006.

FUNARI, Pedro Paulo A.; ROBRAHN-GONZÁLEZ, Erika Marion. Ética, capitalismoe arqueologia pública no Brasil.História. São Paulo, v.2 7, n.2. Franca. 2008. Disponível em:http://www.scielo.br/scielo.php?pid=S010190742008000200002\&script=sci_arttext>. Acesso em 14 jul. 2014.

FUNARI, Pedro Paulo A. OLIVEIRA, Nanci Vieira; TAMANINI, Elizabete. Arqueologia Pública no Brasil e as Novas Fronteiras. Práxis Archaeologica, (3): 131-138, 2008.

INSTITUTO DO PATRIMÔNIO HISTÓRICO E ARTÍSTICO NACIONAL - IPHAN. Instrução Normativa n. 001 , de 25 de março de 2015. Disponível em: http://portal.iphan.gov.br/uploads/ckfinder/arquivos/Instrucao_normativa_01_2015. pdf.>. Acesso em: 30 set. 2015.

LIMA, Leilane Patricia de. Arqueologia e os índios na escola: um estudo de público em Londrina-PR. Tese (Doutorado em Arqueologia). Museu de Arqueologia e Etnologia, Universidade de São Paulo, São Paulo, 2014.

MAGALHÃES, Aloísio. E triunfo? A questão dos bens culturais no Brasil. $2^{\mathrm{a}}$ ed. Rio de Janeiro, Nova Fronteira, Fundação Roberto Marinho, 1997.

McMANAMOM, Francis P. Archaeologycal messages and messengers, Public Archaeology, 1, 5-20, 2000.

MENESES, Ulpiano Bezerra de. Premissas para a formação de políticas públicas em arqueologia. Revista do Patrimônio Histórico e Artístico Nacional. Brasília: IPHAN, nº 33, p. 37-58, 2007.

OLIVEIRA, Cléo Alves P. Educação Patrimonial no Iphan. Monografia de Especialização. Escola Nacional de Administração Pública, Brasília, DF, 2011.

PELEGRINI. Sandra de Cássia Araújo. Cultura e natureza: os desafios das práticas preservacionistas na esfera do patrimônio cultural. Revista Brasileira de História. São Paulo, vol. 26. nº 51, p. 115-140. 2006.

REIS, José Alberione dos. Lidando com as coisas quebradas da história. Revista Arqueologia Pública. São Paulo, n. 2, p. $33-44,2007$. 
ROBRAHN-GONZÁLEZ, Erika Marion. Arqueologia e sociedade no município de Ribeirão Grande, sul de São Paulo: ações em arqueologia pública ligadas ao Projeto de Ampliação da Mina Calcária Limeira. Revista Arqueologia Pública. São Paulo, n.1, p. 63-120, 2006.

SANTOS, Claristella. O compasso da arqueologia em face do avanço da modernidade no Brasil. Achitecton-Revista de Arquitetura e Urbanismo. V.1, n. 1, p.60-67, 2011.

SANTOS, Claristella. CASTRO, Viviane Maria Cavalcanti. LEITE, Marinete Neves. O patrimônio arqueológico rupestre no agreste pernambucano: a comunidade em foco. Revista Arqueologia Pública. Campinas, n. 6, p. 6-16, dez. 2012.

SHANKS, Michael.; TILLEY, Chistopher. Re-ConstructingArchaeology. Cambridge: Cambridge University Press, 1987.

SILVA, Bruno Sanches Ranzani da. Das ostras, só as pérolas: Arqueologia pública e Arqueologia subaquática no Brasil. Mestrado (Mestrado em Antropologia). Universidade Federal de Minas Gerais, Belo Horizonte, 2011.

Recebido em: 08/03/2018 Aprovado em: $31 / 03 / 2018$

Publicado em: 30/11/2018 